\title{
The Impact of Dance-Specific Neuromuscular Conditioning and Injury Prevention Training on Motor Control, Stability, Balance, Function and Injury in Professional Ballet Dancers: A Mixed- Methods Quasi-Experimental Study
}

Katherine L Long, PT, DPT ${ }^{1}$, Mary K Milidonis, PT, PhD², Veronica L Wildermuth, $\mathrm{PT} \mathrm{DPT}^{2}$, Adam N Kruse, $\mathrm{PT}, \mathrm{DPT}{ }^{2}$ Uniqua T Parham, PT, DPT ${ }^{2}$

${ }^{1}$ Cleveland State University; The MetroHealth System, ${ }^{2}$ Cleveland State University

Keywords: motor control, injury prevention, dance medicine, conditioning program, ballet

https://doi.org/10.26603/001c.21150

\section{International Journal of Sports Physical Therapy}

Vol. 16, Issue 2, 2021

\section{Background}

Professional ballet dancers suffer high injury rates and are less likely than other athletes to specifically train to improve muscular strength, coordination, agility, speed and motor control because of heavy training demands, aesthetic appearances and financial barriers.

\section{Hypothesis/Purpose}

The purpose of this study was to examine the effects of a supplemental conditioning program on professional and pre-professional contemporary ballet dancers. The authors hypothesized that those participating in a training program would reduce injury rate by improving their motor control, stability, balance and physical function. The authors aimed to observe the feasibility and qualitative phenomena related to a conditioning program from the dancer's perspective.

\section{Study Design}

A mixed-methods study; within subject quasi-experimental design and qualitative interviews.

\section{Methods}

Six professional classical and contemporary ballet dancers completed the five-week conditioning and injury prevention training program. Non-parametric analysis of baseline, posttest and four-month follow-up physical performance measures, subjective outcomes, and qualitative follow-up interviews, were reported.

\section{Results}

Significant post-test improvements included: The Dance Functional Outcome Survey ( $\mathrm{Z}=$ -2.2, $p=0.04)$, composite Modified Star Excursion Balance Test $(\mathrm{Z}=-2.2, p=0.03$ bilaterally), Single Leg Hop for Distance $(Z=-2.02, p=0.04)$, and Upper Extremity Closed Kinetic Chain Test $(\mathrm{Z}=-2.03, p=0.04)$. Significant changes from baseline to the four-month follow up remained for: (1) Dance Functional Outcome Survey $(\mathrm{Z}=-2.2, p=$ 0.03), (2) Single Leg Hop for Distance ( $\mathrm{Z}=-2.2, p=0.03$ ), and (3) Modified Star Excursion Balance Test composite maximum reach for the left lower extremity $(\mathrm{Z}=-2.2, p=0.03)$.

\section{Conclusion}

Completing a conditioning and prevention program for professional ballet dancers was related to improved function, balance, hop distance/stability and upper extremity

\footnotetext{
Corresponding Author: 
stability. Dancers found the program beneficial, identified barriers to participation, and elucidated factors making the program feasible and successful. More research is necessary to determine the effect of such programs on injury incidence.

\section{Level of evidence}

$3 \mathrm{~b}$

\section{INTRODUCTION}

Ballet dancers are at high risk of sustaining musculoskeletal injuries, especially due to the multitude of technical movements they perform repetitively at extreme ranges of joint motion. Combining both the professional and pre-professional levels, overuse accounts for $65.9 \%$ of dance injuries. ${ }^{1}$ Smith et al. ${ }^{1}$ indicated that amateur and professional dancers have a combined incidence of 1.09 injuries per 1000 dance hours. While several authors have indicated that dance injuries most commonly affect the foot and ankle, ${ }^{1-6}$ the next most commonly injured regions were the lumbosacral spine, ${ }^{7}$ knee, ${ }^{8}$ and hip. ${ }^{9,10}$ These injuries create a substantial burden for dancers and companies alike; the costs of time-loss due to injury, medical expenses, risk of premature retirement, and increased risk for chronic musculoskeletal conditions impact all constituents of the dance community.

Despite the traditional reputation of ballet as an "art," professional dancers are commonly regarded as athletes based on the physical demands they sustain through long hours of technical training, rehearsals, and performances. ${ }^{11}$ Dancers must possess a high level of fitness, strength, coordination, agility, speed, and motor control to perform at the elite level with minimal injury risk. ${ }^{12}$ However, professional ballet dancers are less likely than other athletes to specifically train these areas of fitness. ${ }^{12}$ Dancers commonly teach and work outside of their company dancer positions in order to supplement their limited income from dancing alone. ${ }^{12}$ The additional time, financial and physical constraints associated with their supplemental work limit the feasibility of adding further training to their schedules. ${ }^{12}$ Many dancers may avoid strength and agility training due to the belief that these fitness activities may cause hypertrophy of muscle, negatively impacting their aesthetic appearance. ${ }^{13}$ Subsequently, dancers have been deemed "not as well-conditioned" as other athletes. ${ }^{12,14,15}$ Similar to other sports, the high prevalence for overuse injuries in dance has been linked to strength, aerobic fitness, and motor control deficits. ${ }^{12,13}$ Training programs have been shown to improve such impairments in this population. ${ }^{16}$

Although injury prevention and screening programs for lower extremity injuries have been commonly utilized in sports such as soccer, ${ }^{17,18}$ similar programs have only recently been proposed for professional dancers. ${ }^{12,13,19,20}$ Though initially recommended three decades ago, ${ }^{21}$ the literature regarding the effects of ballet injury prevention programs remains limited, and no studies have sought to standardize the elements of such programs. Initial investigations regarding the benefits of supplemental fitness training showed positive results for decreasing pain, ${ }^{13}$ mixed results for improving aerobic capacity, ${ }^{12,22}$ and no significant strength improvements. ${ }^{12}$ Mistiaen et al. reported positive effects on fitness without affecting aesthetic appearance. ${ }^{13}$ Although dysfunctional movement patterns have been associated with injury, ${ }^{23}$ the effects of motor control training in the professional dance population have not been thoroughly studied.

The purpose of this study was to examine the effects of a supplemental conditioning program on professional and pre-professional contemporary ballet dancers. The authors hypothesized that those participating in a training program would reduce injury rate by improving their motor control, stability, balance and physical function. The secondary purposes were to : (1) determine whether professional ballet dancers' motor control, stability, balance, and physical function improved by participating in a conditioning and injury prevention program, (2) determine if motor control, balance and stability were related to injury incidence, (3) determine if subjective dance-specific function, as measured with the Dance Functional Outcome Survey (DFOS), ${ }^{24}$ correlated with injury in professional and pre-professional contemporary ballet dancers, and (4) observe the feasibility and qualitative phenomena related to a conditioning program from the dancer's perspective.

\section{METHODS}

\section{PARTICIPANTS}

This sample of convenience included uninjured adult dancers from a small professional contemporary ballet company who were recruited through word of mouth and a brochure that was shared with the company. The initial sample consisted of 11 dancers: eight professionals, one apprentice and two trainees. Participation was voluntary. All subjects who elected to participate granted informed consent. Anonymity and confidentiality were maintained throughout the study. Two dancers from the initial sample were excluded due to sustaining dance-related injuries prior to the start of the training program.

\section{STUDY DESIGN}

The study was a mixed methods quasi-experimental design with a volunteer sample of professional dancers from one company. The project was approved by the Cleveland State University Institutional Review Board. The final sample consisted of six dancers who were informed that data would be submitted for publication. Subject confidentiality was protected. A power analysis to determine sample size was not possible in this study. Dancers are a unique athletic population. Previous data with estimates of difference or variance for dancers and these outcome measures were not available to perform a power analysis prior to this feasibility study. 


\section{DEMOGRAPHICS AND DANCE EXPERIENCE}

Characteristics of the sample were collected via survey on the day of baseline testing. Dancers were asked for their age, gender, highest level of education, and years of dance experience.

\section{DANCE FUNCTIONAL OUTCOME SURVEY}

All dancers completed the DFOS at baseline, immediately post-conditioning class, and at the four-month follow-up. The DFOS is currently the only dance-specific subjective functional outcome measure and focuses on general activities of daily living and dance-specific technique. Very recent investigations ${ }^{25}$ regarding the psychometric properties of this tool revealed high test-retest reliability, internal responsiveness over time, sensitivity and internal consistency. The DFOS demonstrated strong construct validity (vs. SF-36 PCS), scale uni-dimensionality, and the absence of both floor and ceiling effects. ${ }^{25}$

\section{PHYSICAL PERFORMANCE TESTS}

A battery of physical performance tests (PPTs) was performed at baseline prior to beginning the conditioning class, within the week following completion of the last class, and at a four-month follow-up. The PPTs selected were previously validated as effective measures of balance, stability, and motor control. ${ }^{23,26-28}$ They were performed as described by the authors listed in Table 1, with testing completed by the same raters at baseline and each subsequent testing period.

\section{NEUROMUSCULAR CONDITIONING AND INJURY PREVENTION CLASS}

The conditioning and injury prevention class was performed in the studio twice a week for 30 minutes over the course of five weeks, with the first session each week taught by a licensed physical therapist who was board certified in orthopedics. The second supplemental session each week was led by one dancer liaison who attended the class earlier in the week. The selected dancer had experience teaching group exercise classes. She reviewed the exercises with the dancers with the guidance of a handout outlining the program.

The neuromuscular conditioning and injury prevention class was developed together by the board certified orthopedic physical therapy specialist who taught the class, and the physical therapist specialty-trained in strength and conditioning. Similar to previous programs, ${ }^{12,13}$ this course began with basic movement pattern injury prevention exercises known to be effective in other sport populations. ${ }^{29,30}$ It initially emphasized mechanics and correction of movement faults with basic exercises such as bridges, planks, single leg deadlifts, lunges, squats, step ups, and jumping. The program then progressed to more dance-specific movement system patterns as the course advanced (Appendix 1). The full program consisted of a dynamic warm-up, agility training, plyometrics and strength training (Table 2). Previous authors have recommended that injury prevention programs include these components. ${ }^{18,31,32}$ As suggested pre-
Table 1: Physical Performance Tests

\begin{tabular}{|c|c|}
\hline Variable & Description \\
\hline Motor control & $\begin{array}{l}\text { 2 Motor control tests: } \\
\text { 1. Knee Lift Abdominal Test } \\
\text { 2. Standing Bow }\end{array}$ \\
\hline Balance & $\begin{array}{l}\text { Modified Star Excursion Balance } \\
\text { Test }^{\dagger}\end{array}$ \\
\hline $\begin{array}{l}\text { Ankle and Knee } \\
\text { Stability }\end{array}$ & One Leg Hop for Distance ${ }^{\dagger}$ \\
\hline Hip Stability & Medial Triple Hop Test ${ }^{\dagger, \ddagger}$ \\
\hline $\begin{array}{l}\text { Upper Extremity } \\
\text { Stability }\end{array}$ & $\begin{array}{l}\text { Closed Kinetic Chain Upper } \\
\text { Extremity Stability Test }{ }^{\S}\end{array}$ \\
\hline
\end{tabular}

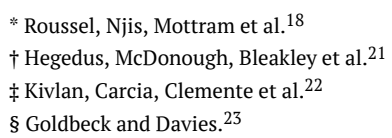

viously, ${ }^{18,31}$ verbal and tactile feedback to correct faulty movement patterns were given concurrently while performing each exercise. Dancers were educated regarding the targeted anatomical regions, desired movement patterns, typical compensations, likely mechanisms for injury, intervention rationale, and how the techniques might both reduce injury and enhance performance. Dancers were taught how basic component training was relevant to and translated to improving their traditional ballet combinations.

\section{STATISTICAL ANALYSIS}

Inferential statistics. Changes between baseline and postconditioning PPTs were assessed using the Wilcoxon signed-rank test, which is a paired difference test of mean rank used for single sample, repeated measurements. Statistical significance was set at $p<0.05$. This non-parametric test is inherently conservative and is used with small sample sizes to reduce assumptions about data distribution normality. 33

\section{QUALITATIVE ANALYSIS}

Phenomenological interview. The purpose of this mixed methods phenomenological analysis was to understand the experience or phenomenon from the dancers' point of view. The researchers were interested in learning if dancers felt a cross training program had benefits and value. If conditioning was beneficial, what recommendations were there for other dancers? This information was obtained through structured interviews by one researcher four months after the conditioning program. The 30-minute interview consisted of eight open-ended qualitative questions. All interviews were audio recorded and transcribed by a member of the research team who did not teach the program, interview dancers, or develop the study design.

Phenomenological analysis. To maximize credibility of the study, several methods were used: triangulation of researchers' interpretations, sampling for diverse perspec- 
Table 2: Complete 5-week Conditioning Program

\begin{tabular}{|c|c|c|c|c|}
\hline \multirow[t]{2}{*}{ Week } & \multicolumn{4}{|l|}{ Exercises } \\
\hline & Warm Up & Plyometrics & Agility & Strength \\
\hline 1 & $\begin{array}{l}\text { - } \text { Forward jogging } \\
\text { - High knees } \\
\text { - } \text { Butt kicks } \\
\text { - } \text { Alternating front } \\
\text { kick with toe touch } \\
\text { - } \text { Alternating heel } \\
\text { walk dynamic ham- } \\
\text { string stretch with } \\
\text { toe reach }\end{array}$ & $\begin{array}{ll}\text { - Jumps scissor } \\
\text { - } \quad \text { Wump } \\
\text { - } \quad \text { DL holl Taps for- } \\
\text { ward, back- } \\
\text { ward and over } \\
\text { lateral line } \\
\text { - Controlled } \\
\text { step down } \\
\text { from stage } \\
\text { - Step up onto } 2 \\
\text { ft stage }\end{array}$ & $\begin{array}{l}2 \text { ladder lengths each: } \\
\text { - Forward SL hops } \\
\text { - Lateral SL hops } \\
\text { - Medial SL hops two feet left, } 1 \text { foot in, } 2 \\
\text { feet right }\end{array}$ & $\begin{array}{l}\text { - } \text { High plank } \\
\text { - } \text { Side plank each side } \\
\text { eral UE shoulder flexion } \\
\text { - } \text { holds } \\
\text { - } \text { Straight leg raises } \\
\text { - } \text { Squates } \\
\text { - } \text { curl } \\
\text { - } \text { Pistol squats } \\
\text { - } \text { der press } \\
\text { - } \text { Push Romanian deadlif overhead shoul- } \\
\text { - Bench dips } \\
\text { - Inverted rows at bar }\end{array}$ \\
\hline 2 & $\begin{array}{l}\text { - Alternating front } \\
\text { kick with toe touch } \\
\text { - } \text { Alternating heel } \\
\text { walk dynamic ham- } \\
\text { string stretch with } \\
\text { toe reach } \\
\text { - Carioca } \\
\text { - High Knee Skip }\end{array}$ & 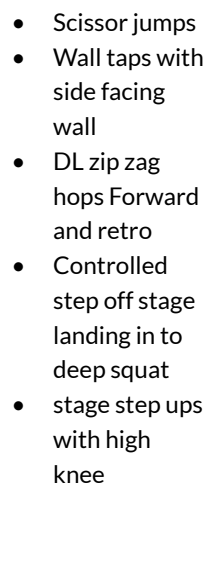 & $\begin{array}{l}2 \text { ladder lengths each: } \\
\text { - Forward SL hops } \\
\text { - Lateral SL hops } \\
\text { - Medial SL hops two feet left, } 1 \text { foot in, } 2 \\
\text { feet right }\end{array}$ & $\begin{array}{l}\text { - } \text { High to low plank } \\
\text { - } \text { Side-plank with hip dip/raise } \\
\text { eral UE shoulder flexion/bi- } \\
\text { lateral LE extension holds } \\
\text { - } \text { Bridges with marching } \\
\text { - } \text { Backwards lunge } \\
\text { - } \quad \text { SL Romanian deadlift with } \\
\text { - } \text { arms forward } \\
\text { - } \text { opush up (isometric hold) with } \\
\text { - Bench dips (isometric hold } \\
\text { - } \text { with tip toes) } \\
\text { - OveraBand rows } \\
\text { Band }\end{array}$ \\
\hline 3 & $\begin{array}{ll}\text { - } & \text { Jogging } \\
\text { - } & \text { Marching } \\
\text { - } & \text { Lateral shuffle (face } \\
\text { - } & \text { Lame direction) } \\
\text { - } & \text { down \& back) } \\
\text { - } & \text { "Inchworm" for- } \\
\text { ward fold to high } \\
\text { plank walkout (1x } \\
\text { down \& back) }\end{array}$ & $\begin{array}{l}\text { - Grand plie } \\
\text { squat jump } \\
\text { - } \text { Split squat } \\
\text { jump } \\
\text { - } \text { Alternate leg } \\
\text { push off } \\
\text { - Drop freeze }\end{array}$ & $\begin{array}{l}2 \text { ladder lengths each: } \\
\text { - Hopscotch } \\
\text { - Lateral SL hops (skip a box) } \\
\text { - Medial SL hops (skip a box) } \\
\text { - start both feet in: right lateral out, left } \\
\text { forward, right forward in, left lateral } \\
\text { out, right forward, left forward in (re- } \\
\text { peat) }\end{array}$ & $\begin{array}{l}\text { - SL squat reaching in anterior, } \\
\text { medial, lateral, and posterior } \\
\text { directions with non-stance } \\
\text { leg } \\
\text { - } \quad \text { Pilates roll out (eccentric ab- } \\
\text { dominals) } \\
\text { - SL stiff leg deadlift with arms } \\
\text { overhead } \\
\text { - High plank opposite knee to } \\
\text { opposite elbow } \\
\text { - Relevé lunge-hold into for- } \\
\text { ward lunge, right lunge, back- } \\
\text { wards lunge, left lunge } \\
\text { Reverse crunches }\end{array}$ \\
\hline 4 & $\begin{array}{l}\text { - } \text { Alternating front } \\
\text { - } \text { kick with toe touch } \\
\text { - High knee skip } \\
\text { - Lunge with over- } \\
\text { - } \text { head side reach } \\
\text { "Inchworm" for- } \\
\text { ward fold to high } \\
\text { plank walkout }\end{array}$ & $\begin{array}{ll}\text { - } & \text { Single-arm al- } \\
\text { ternate leg } \\
\text { bound } \\
\text { - } & \text { DL box jumps } \\
\text { - } & \text { Drop Freeze } \\
\text { - } & \text { Depth jumps } \\
\text { with lateral } \\
\text { movement } \\
\text { - } \quad \text { SL forward } \\
\text { hops for dis- } \\
\text { tance } \\
\text { - SL medial hop } \\
\text { for distance }\end{array}$ & $\begin{array}{l}2 \text { ladder lengths each: } \\
\text { - } \quad \text { Forward SL hops with arms behind back } \\
\text { - Lateral SL hops (skip a box) } \\
\text { - } \quad \text { Medial SL hops (skip a box) }\end{array}$ & $\begin{array}{l}\text { - Y Balance SL Squat: -anterior, } \\
\text { posterior-medial, \& poste- } \\
\text { rior-lateral directions } \\
\text { - SL stiff leg deadlift with arms } \\
\text { overhead and calf raise } \\
\text { - } \quad \text { Relevé lunge -hold into for- } \\
\text { ward, right, retro, \& left } \\
\text { lunge } \\
\text { - } \text { Bridges- hips abducted vs } \\
\text { TheraBand \& alternating hip } \\
\text { flexion } \\
\text { - Plank bird dog } \\
\text { Push up with contralateral } \\
\text { hand taps } \\
\text { - TheraBand rows } \\
\text { TheraBand horizontal abduc- } \\
\text { tion }\end{array}$ \\
\hline
\end{tabular}




\begin{tabular}{|c|c|c|c|c|}
\hline & & & & $\begin{array}{l}\text { D2 Flexion with TheraBand } \\
\text { (lower trapezius emphasis) }\end{array}$ \\
\hline 5 & $\begin{array}{l}\text { - Alternating front } \\
\text { - } \text { ick with toe touch } \\
\text { - Hutt Kickers } \\
\text { - High knee skip } \\
\text { - Lunge with twist } \\
\text { - "Inchworm" for- } \\
\text { ward fold to high } \\
\text { plank walkout }\end{array}$ & $\begin{array}{l}\text { - } \quad \text { Foot touches } \\
\text { - SL box jumps } \\
\text { - } \text { SL Depth } \\
\text { jump } \\
\text { - } \text { forward SL } \\
\text { hop for dis- } \\
\text { tance } \\
\text { - } \\
\text { Medial SL hop } \\
\text { for distance }\end{array}$ & $\begin{array}{l}2 \text { ladder lengths each: } \\
\text { - } \quad \text { Forward SL hops } \\
\text { - Lateral SL hops } \\
\text { - } \quad \text { Medial SL hops }\end{array}$ & $\begin{array}{l}\text { - Y Balance SL Squat: -anterior, } \\
\text { posterior-medial, \& poste- } \\
\text { rior-lateral directions } \\
\text { - Reaching Rond de Jambe } \\
\text { - Relevé lunge -hold into for- } \\
\text { ward, right, retro, \& left } \\
\text { lunge } \\
\text { - Relevé Plié }\end{array}$ \\
\hline
\end{tabular}

$\mathrm{DL}=$ double leg, $\mathrm{UE}=$ upper extremity, $\mathrm{SL}=$ single leg, $\mathrm{LE}=$ lower extremity

tives, and rich descriptions to support thematic categories. First, each transcript was reviewed by the authors individually to look for key phrases in each interview question. Next, the authors met as a group to confirm the key phrases found in each interview question and compile the results. Then, the authors reviewed the key phrases individually to look for main themes in each question across all subjects. The main themes that each individual determined for each interview question were placed in a table organized by the eight guiding questions. The group agreed upon the main themes.

Injury tracking. Injury tracking within the study period was conducted via survey at the four-month follow-up interview. Dancers indicated any time lost from dance ${ }^{11}$ or time requiring modified activity ${ }^{34}$ during the course and four-month follow-up period.

\section{RESULTS}

\section{SUBJECTS}

Of the 11 dancers initially tested, five dancers did not complete the program. Two were excluded prior to the start of the study. Three additional dancers dropped out for the following reasons: (1) concern regarding previous surgeries, (2) a leave of absence from the company, and (3) schedule constraints. Thus, the final sample consisted of six dancers. Descriptive statistics for participating subjects were calculated (Table 3).

\section{INFERENTIAL FINDINGS}

Post-conditioning. Results from the Wilcoxon signed-rank tests for baseline to post-conditioning change in the DFOS and PPTs are included in Table 4. Statistically significant changes for the DFOS and three of the six PPTs were found. Immediately following the conditioning program, the DFOS was significantly improved $(p=0.04)$. Dancers also showed improved balance on the composite Modified Star Excursion Balance Test (mSEBT) bilaterally ( $p=0.03$ for both the right and left lower extremity), improved Single Leg Hop for Distance $(p=0.04)$, and improved performance on the Upper Extremity Closed Kinetic Chain Test $(p=0.04)$. No statistically significant changes were noted with the KLAT, Standing Bow Test, or the Medial Triple Hop Test.

Four-month follow-up. Statistically significant changes from initial testing to the four-month follow-up remained
Table 3: Descriptive Statistics

\begin{tabular}{ll}
\hline Descriptive Statistics & \\
\hline Education & \\
College & $50 \%$ \\
Some College & $33 \%$ \\
High School & $16 \%$ \\
Gender & \\
Male & $33.30 \%$ \\
Female & $66.70 \%$ \\
Dance Training & \\
10-12 years & $50 \%$ \\
17-20 years & $50 \%$ \\
Professional Dancer & $66.70 \%$ \\
Apprentice/ Trainee & $33.30 \%$ \\
Age & \\
Mean & 22.8 (SD 1.47) \\
\hline
\end{tabular}

for the following tests: (1) DFOS ( $p=0.03$ ), (2) Single leg hop for distance $(p=0.03)$, and (3) mSEBT composite maximum reach for the left lower extremity $(p=0.03)$. The Upper Extremity Closed Kinetic Chain test $(p=0.08)$ and the mSEBT composite reach right $(p=0.08)$, and anterior reach right $(p=0.12)$ and left $(p=0.23)$ were not statistically significantly different from baseline (Table 4). Furthermore, none of the tests found non-significant at the initial followup became statistically significant at the four-month follow-up.

\section{QUALITATIVE FINDINGS}

Findings from the phenomenological analysis of the followup interview were categorized into common themes across the questions (Table 5). Half of the participants reported they were motivated to participate in the conditioning course to improve their performance. With respect to strengths and limitations, $83.3 \%$ of dancers believed their leg strength and endurance were their strongest attributes, and $66.7 \%$ reported their stability, balance and landing technique with jumping were their greatest limitations. The dancers found exercises targeting core stability (66.7\%), upper body strength (50\%) and leg strength (50\%) to be the 
Table 4: Means and Pre-test to Post-test Wilcoxon Signed-Rank Tests

\begin{tabular}{|c|c|c|c|c|c|c|c|}
\hline \multirow[t]{2}{*}{ Test } & \multirow{2}{*}{$\begin{array}{l}\text { Pre- } \\
\text { Test } \\
\\
\text { Mean } \\
\text { (SD) }\end{array}$} & \multirow{2}{*}{$\begin{array}{l}5 \text { Week } \\
\text { Follow- } \\
\text { Up } \\
\text { Mean } \\
\text { (SD) }\end{array}$} & \multirow{2}{*}{$\begin{array}{l}4 \\
\text { Month } \\
\text { Follow- } \\
\text { Up } \\
\text { Mean } \\
\text { (SD) }\end{array}$} & \multicolumn{2}{|c|}{$\begin{array}{l}\text { Pre-Test to } 5 \text { Week } \\
\text { Follow-Up }\end{array}$} & \multicolumn{2}{|c|}{$\begin{array}{l}\text { Pre-Test to } 4 \\
\text { Month Follow-Up }\end{array}$} \\
\hline & & & & Z & $p$-value & Z & $p$-value \\
\hline $\begin{array}{l}\text { mSEBT Composite } \\
\text { Maximum Reach Right (cm) }\end{array}$ & $\begin{array}{l}260.08 \\
(18.0)\end{array}$ & $\begin{array}{l}291.58 \\
(30.50)\end{array}$ & $\begin{array}{l}273.33 \\
(28.86)\end{array}$ & -2.2 & $0.028^{*}$ & -1.7 & 0.075 \\
\hline $\begin{array}{l}\text { mSEBT Composite } \\
\text { Maximum Reach Left (cm) }\end{array}$ & $\begin{array}{l}260.96 \\
(17.6)\end{array}$ & $\begin{array}{l}296.58 \\
(34.25)\end{array}$ & $\begin{array}{l}276.41 \\
(27.20)\end{array}$ & -2.2 & $0.028^{*}$ & -2.2 & $0.028^{*}$ \\
\hline $\begin{array}{l}\text { mSEBT Maximum Anterior } \\
\text { Reach Right }(\mathrm{cm})\end{array}$ & $\begin{array}{l}64.33 \\
(1.94)\end{array}$ & $\begin{array}{l}76.91 \\
(12.65)\end{array}$ & $\begin{array}{l}71.5 \\
(10.94)\end{array}$ & -1.99 & $0.046^{*}$ & -1.57 & 0.116 \\
\hline $\begin{array}{l}\text { mSEBT Maximum Anterior } \\
\text { Reach Left }(\mathrm{cm})\end{array}$ & $\begin{array}{l}66.42 \\
(3.29)\end{array}$ & $\begin{array}{l}79.75 \\
(15.09)\end{array}$ & $\begin{array}{l}71.1 \\
(10.87)\end{array}$ & -2.21 & $0.027^{*}$ & -1.214 & 0.225 \\
\hline $\begin{array}{l}\text { Single Leg Hop for Distance } \\
(\mathrm{cm})\end{array}$ & $\begin{array}{l}119.59 \\
(12.32)\end{array}$ & $\begin{array}{l}147.63 \\
(25.02)\end{array}$ & $\begin{array}{l}145.70 \\
(17.23)\end{array}$ & -2.02 & $0.043^{*}$ & -2.2 & $0.028^{*}$ \\
\hline $\begin{array}{l}\text { Closed Kinetic Chain Upper } \\
\text { Extremity Stability Test } \\
\text { (taps } / 15 \mathrm{sec} \text { ) }\end{array}$ & $\begin{array}{l}25.44 \\
(3.18)\end{array}$ & $\begin{array}{l}31.27 \\
(4.28)\end{array}$ & $\begin{array}{l}27.5 \\
(2.69)\end{array}$ & -2.03 & $0.042^{*}$ & -1.78 & 0.075 \\
\hline Medial triple hop Right (cm) & $\begin{array}{l}407.81 \\
(41.13)\end{array}$ & $\begin{array}{l}402.44 \\
(65.75)\end{array}$ & $\begin{array}{l}394.08 \\
(70.22)\end{array}$ & -0.14 & 0.893 & -0.943 & 0.345 \\
\hline Medial Triple Hop Left (cm) & $\begin{array}{l}417.55 \\
(50.52)\end{array}$ & $\begin{array}{l}408.58 \\
(79.9)\end{array}$ & $\begin{array}{l}398.16 \\
(88.25)\end{array}$ & -0.37 & 0.715 & -0.734 & 0.483 \\
\hline $\begin{array}{l}\text { Dance Functional Outcome } \\
\text { Scale }\end{array}$ & $\begin{array}{l}80.17 \\
(5.26)\end{array}$ & $\begin{array}{l}83.16 \\
(3.92)\end{array}$ & $\begin{array}{l}85.5 \\
(4.08)\end{array}$ & -2.2 & $0.042^{*}$ & -2.2 & $0.028^{*}$ \\
\hline Standing Forward Bow & $\begin{array}{l}\text { All full \& } \\
\text { painless }\end{array}$ & $\begin{array}{l}\text { All full \& } \\
\text { painless }\end{array}$ & $\begin{array}{l}\text { All full \& } \\
\text { painless }\end{array}$ & $\begin{array}{l}\text { No } \\
\text { significant } \\
\text { change }\end{array}$ & $\begin{array}{l}\text { No } \\
\text { significant } \\
\text { change }\end{array}$ & & \\
\hline $\begin{array}{l}\text { Abdominal Knee Lift Test } \\
\text { Right }(\mathrm{mmHg})\end{array}$ & $\begin{array}{l}9.00 \\
(4.8)\end{array}$ & $\begin{array}{l}12.00 \\
(3.57)\end{array}$ & $\begin{array}{l}13.33 \\
(7.0)\end{array}$ & -1.38 & 0.17 & -1.35 & 0.176 \\
\hline $\begin{array}{l}\text { Abdominal Knee Lift Test } \\
\text { Left }(\mathrm{mmHg})\end{array}$ & $\begin{array}{l}11.0 \\
(7.1)\end{array}$ & $\begin{array}{l}16.83 \\
(10.04)\end{array}$ & $\begin{array}{l}8.0 \\
(2.82)\end{array}$ & -1.21 & 0.23 & -0.736 & 0.462 \\
\hline
\end{tabular}

most beneficial exercises, while $66.7 \%$ of those same participants reported they no longer continued doing core exercises, specifically bridges and planks, after the course ended.

The dancers did express concern regarding several barriers which may preclude their participation in similar conditioning classes. Most notably, $83.3 \%$ of those interviewed reported that time was their greatest barrier. The convenience of this course being brought to them made it more feasible to fit into their schedules. Money and scheduling were also major concerns, with $66.7 \%$ of dancers reporting these obstacles to participating. Even with these barriers considered, the participants unanimously agreed that the course was beneficial for both professional and pre-professional dancers. This group was evenly split, with $50 \%$ reporting it would be most beneficial for dancers before $8^{\text {th }}$ grade, while the other $50 \%$ noted it would be best suited to target older dancers in $8^{\text {th }}$ grade or above. All 6 dancers reported no time loss due to injury. None of the participants reported a need to modify their dance activity secondary to injury.

\section{DISCUSSION}

Many authors have proposed the need for supplemental conditioning programs to improve dancers' fitness and decrease injury risk factors. ${ }^{12,13,19-21}$ However, minimal research exists outlining conditioning program design, or the effects of such programs on injury risk factors. It was hypothesized that using a conditioning program similar to other injury prevention programs for mainstream athletics, with some dance-specific components, would improve physical function in areas previously identified as predicting injury in other sports, as well as dancers' perception of their function. Investigating the effects of risk-factor specific conditioning on validated physical performance measures is crucial for determining how such programs may or may not influence injury risk factors. It is a necessary preliminary step to determining the effects of such conditioning programs on injury incidence and attempting to design a program that might be utilized by dance companies to minimize overuse injuries.

This study is the first to investigate the impact of neuromuscular conditioning on dance function, motor control, stability and balance in professional and pre-professional ballet dancers. A mixed-methods model was used to gain a more thorough understanding of the results and how the proposed conditioning program influenced the dancer participants. Following the dance-specific conditioning program, improvements were noted in dance function, knee/ 


\section{Questions}

\section{What motivated you to participate in this study?}

Knowing baseline/limitations ( $16.67 \%$ of participants)

- "I wanted to as a dancer, see where my baseline level was."

Helping limitations become strengths (33.33\% of participants)

- "I think as dancers, we all want to know our bodies really well. We want to know our strengths and our limitations. We want to know how to help the limitations become strengths."

Cross training opportunity (33.33\% of participants)

- "Well for one I wanted to cross train. That's always a priority, as dancers, so we can keep our bodies functioning to the highest capacity."

Improve performance (50\% of participants)

- "Well as a dancer my body is definitely my instrument, so I am always looking for new ways to improve it and make it better and make it function at the highest capacity that it can. So, when I [had] the opportunity to work...in ways I had never worked before it was a no brainer, I had to jump on it."

What did you learn about your physical capacity, strengths, and limitations through participation in the class?

They learned their strengths were leg strength and endurance. (83.33\% of participants)

- "My strength. I am stronger than I thought on my legs, jumping and landing on one foot."

- " "My legs are strong. And I wouldn't say necessarily strength, but also endurance. I can really exert myself."

They learned their limitations were balance/stability and jumping/landing technique (66.67\% of participants)

- "My limitations were just landing on this left ankle- so some of the jump strength trainings, that we did, which was important, I just couldn't really get through all that."

- " "I found that my arms and upper body need to be strengthened."

- "I feel that a lot of times with impact I lack control and my flexibility tends to get the best of me and so these exercises were very helpful in realizing where my alignment was off and where I needed to work on strengthening and what exactly my body was doing."

- "Balance was another thing that I found that I wasn't aware that I was weaker in."

\section{What exercises, if any, did you find to be most beneficial or meaningful?}

\section{Core stability/abdominals $(66.67 \%$ of participants)}

- "Definitely the different stability exercises we did such as the one-legged squats, we did a lot of bridges on the floor, things like that. Planking, a lot of that kind of thing was really helpful just because those are exercise that I think as dancers we all know we should do but we don't devote the time to them."

Ankle/Leg focus on stability (33.33\% of participants)

- "Definitely all of the single leg jumps, and single leg fall downs, when we would stand up on the stage and come down on one foot and jumps up."

Upper body strength (50\% of participants)

- "I loved the work with the bands...upper body training with the Thera Bands...new core activities."

Leg/quad strength ( $50 \%$ of participants)

- "The lateral jumping that we did across the floor helped. I could strengthen my muscles and the outside of my legs; it aided in balance, which was one of my limitations."

\section{What exercises from the class, if any, do you still perform and why?}

Core exercises (Bridges/Planks) (66.67\% of participants)

- "Really anything that really isolated one leg as opposed to both.... a lot of the other stability stuff like the bridges and planks."

Stopped doing most exercises (16.67\% of participants)

- "I stopped doing most of them."

Lunges (33.33\% of participants)

- "Again, things that I struggled with like any kind of one-legged squat, for sure, or lunge." 2

- " "I do some of the alternating lunges and some of the upper body strength that we did with TheraBands."7

\section{What do you see as possible barriers for professional dancers to do a similar conditioning class?}

Time - Fitting in (unless brought to us) (83.33 of participants)

- Time - working a million jobs and timing of classes

- Difficult to get to a class unless it is brought to us

Money - organizational companies don't provide it, can't afford teachers, can't afford classes on own) (66.67\% of participants)

- Organizational - "most companies don't respect it to put it into the schedule or they are maximizing time for dance specific things"

- Money - "organization funds, company doesn't have funds to pay a teacher or a fitness facility."

- Barriers are money - "free for us, but if we had to pay it would be a deal breaker."

Scheduling - time of day (not good before class) (66.67\% of participants)

- "Different schedules to coordinate group class."

- " "Before class was a challenge because impact from jumping was a little much with the addition of what dancers were already doing."

- "Timing - we would like to do it at the end of the day, so we don't fatigue before class."

\section{Would you recommend similar conditioning classes for dancers at your level and why?}

Unanimous yes- liked doing the class in a group (increased motivation and comradery of organization), shows limitations, helps improve strength, stability and balance. (100\% of participants)

- "Yes, aided in comradery and brought the organization together, increased motivation and energy."

- "Yes, definitely, it is a good balance and it keeps you healthy. Prefer to do it as a group because of the energy and motivation".

- "Would recommend conditioning classes for dancers at our level because cross training is important." 
- "Yes - helped find exercises to help with limitations; helped alignment, helped improve balance and strength, knees to toes." Would you recommend a conditioning class with similar principles for any other level(s) of dance and why?

Yes - important before professional level (100\% of participants)

Half said as kids to develop good technique young (before 8 th grade) ( $50 \%$ of participants)

- "Recommend for all levels of dance and preventing setting up bad habits."

- "Yes, at all levels, especially lower levels and all other forms of dance. Lower levels because if you start right with the basics you can perform easier."

- "Absolutely, especially when you are a kid...Building strength from a young age would teach us how and why our bodies work the way that they do."

Half said 8th grade and older through trainee, pre-professional levels including high school and college (50\% of participants)

- "With students a conditioning class should be done weekly, definitely for 8th grade and up. Younger levels (elementary) are building coordination and motor skills, while in middle school and 8th grade, they can build their concept of alignment."

- " "Recommend to kids teaching now, but hard to teach a 12-year-old to get involved with this on their own."

- "Recommend for trainee or apprentice like pre-professional students to bridge the gap to a professional dancer. Pre-professional dancers are more likely over exert themselves and get injured. A class like this would open their eyes and make them less inclined to injury as they continue to push."

Is there anything else you wish the conditioning class would have covered?

More core stabilization and less impact/jump training (33.33\% of participants)

- " "Definitely work on upper body strength and core stabilization more than jump training."

- "More core stability/more low impact rather than jumps."

Could have been more dance specific (33.33\% of participants)

- "The active stretching/Pilates/yoga for warm up could be more dance specific."

- "Individualized exercise for dancers. Could be even more ballet specific."

Table 6: Knee Lift Abdominal Test Pressure Variation Comparisons

\begin{tabular}{|c|c|c|c|c|}
\hline & \multicolumn{2}{|c|}{$\underline{\text { Left Side }}$} & \multicolumn{2}{|c|}{$\underline{\text { Right Side }}$} \\
\hline & Mean & Range & Mean & Range \\
\hline Current Study (mmHg) & 11 & $4-24$ & 9 & 4-18 \\
\hline Previous Study $(\mathrm{mmHg})^{*}$ & 48 & $44-60$ & 47.2 & $44-54$ \\
\hline
\end{tabular}

ankle stability and balance, but not in lumbo-pelvic motor control or hip stability. The phenomenological analysis provided insight into perceived benefits of the program, motivation for and barriers to participation in similar conditioning programs. For example, dancers reported which conditioning exercises were perceived as most beneficial, and which exercises were continued independently after the program. They were most motivated to learn of their strengths and weaknesses, and methods to improve upon their limitations. The most common barriers to such programs are time and money. All dancers would recommend similar conditioning classes to other dancers.

Previous research investigated the effects of a conditioning program, which included motor control training, endurance, and strength training, on aerobic capacity and strength. ${ }^{12}$ The chosen interventions did not yield significant improvements with the study's included objective test measures, but their measures did not examine the effect of the program on motor control. The same lead author ${ }^{23}$ previously described the KLAT and standing bow test as motor control measures which could predict injury in the lower extremities and lumbar spine. A similar lack of improvement with these same tests was noted here. While the KLAT and Standing Bow Test were validated for predicting injury in the original study, ${ }^{12}$ baseline measures in the current sample showed much less pressure variation (Table 6) and higher performance, respectively.

These findings indicate that these measures may have an inherent ceiling effect and may not be sensitive-enough for professional dancers. It is possible that, because of their initially superior scores and lack of injury incidence during the study period, the dancers in this study also had a decreased injury risk compared to those studied previously. ${ }^{12}$ If such is the case, further development of more sensitive dance-specific PPTs for motor control and stability in professional-level dancers may be warranted. Improvements were noted in balance and knee/ankle stability, as evidenced by improvements in the mSEBT and the Single Leg Hop for Distance test, respectively. While the SEBT and Y-balance tests have been widely studied, only four publications prior to 2016 used one of these tools to investigate injury risk in sport. ${ }^{17}$ These studies demonstrated that a mSEBT combined score of less than $94 \%$ of the contralateral lower extremity increased lower extremity injury odds by 6.5 in high school female athletes, and injury odds were 2.7 times more likely with greater than a $4 \mathrm{~cm}$ asymmetry difference with anterior reach in male and female high school athletes. ${ }^{17,26,35}$ Hegedus et al. ${ }^{26}$ also reported moderate evidence that the Single Leg Hop for Distance test can discriminate between athletes who do and do not have ankle/ knee instability. Considering these previous findings, the current improvements in the mSEBT and Single Leg Hop for 
Distance following conditioning may indicate decreased injury risk due to gains in balance and ankle/knee stability, respectively. Despite a very small sample size, dance and general function as indicated by the DFOS were also improved following the program, demonstrating the strong responsiveness of this new tool, which was validated recently in a larger-sample study. ${ }^{25}$ The findings in the current study support the previous idea that applying sports medicine principles may decrease injury risk in the dance population. ${ }^{19}$ Continued participation in injury prevention programs throughout a season has been recommended in traditional athletics including, but not limited to, soccer. ${ }^{31}$ Similar independent continuation of the conditioning program may have better maintained the physical performance test improvements into the four-month follow-up period.

Previously, the utility of dance screening programs for injury prediction and prevention was questioned, 36 mainly because standard measures from an orthopedic setting (i.e., subjective history, flexibility and strength testing) did not detect between injured and non-injured dancers and were considered too generic for this population. Similar to previous recommendations, ${ }^{37,38}$ we focused our screening on functional PPTs measuring complex interactions of movement and evaluated function with the only currently validated dance-specific subjective outcome measure. Further, dancers in this study identified their jump/landing strategies as limitations. Many indicated this was a beneficial aspect of the program, but several also recommended limiting the jump/landing focus in future conditioning programs. These findings suggest that emphasis on these strategies was meaningful, but some dancers were uncomfortable with the dosage implemented in training. Allen indicated that training for jump/landing strategy can decrease injury risk, but that too much fatigue from jumping may increase injury risk. ${ }^{34}$ Many of the dancers also reported that they often do not participate in cross-training as much as they would like secondary to time and money constraints. They indicated that bringing the current program to their studio and offering it without a charge increased their willingness to participate, even though it was an additional time commitment. Past researchers suggested that dance companies should be aware of and consider the financial consequences resulting from injuries. ${ }^{39}$ Perhaps appreciating this impact and implementing similar conditioning programs within dance company schedules may serve as a tool to decrease overall long-term costs and improve dancers' career longevity. Financial resources are typically more readily available in larger companies, increasing their likelihood of adopting supplemental training. More overuse injuries are often found in smaller companies with limited budgets, where dancers are more frequently encouraged to dance through injury due to a lack of understudies. ${ }^{20}$ Perhaps adopting a sports medicine approach to preventing injuries is most important in these small companies where injuries are more prevalent. Finally, all the dancers suggested that similar conditioning programs begin at least by the pre-professional level, consistent with previous recommendations to begin with adolescent dancers. ${ }^{40}$

While the first objective was analyzed thoroughly, the second and third secondary purposes could not be investigated because none of the dancers reported injury, based on the "time loss" and "modified activity" injury definitions. ${ }^{11}$ However, additional questioning revealed that while these dancers denied injury and reported an average $0-1 / 10$ pain on a visual analog scale at rest, all reported between 3-6/10 average pain with activity during the study period. The data imply that the dancers consistently work through pain, and that moderate levels of pain do not necessarily signify injury to this sample. These results further support the need to develop an improved consensus definition to track injury, ${ }^{11}$ and suggest the need to investigate further the implications of the "dancer mentality" 11,41 on pain and injury perception in dancers. Russel et al. ${ }^{11}$ expressed that injury risk is increased in dancers whose personalities allow them to dance through pain, and that this characteristic typically coincides with the dancer's level of success. This thought may implicate the need for further focus on injury prevention for those dancers most likely to fill principle roles.

\section{LIMITATIONS}

This study had inherent limitations due to the self-reported nature of injury tracking with the DFOS, and the test-retest design. The within-subjects design eliminated the possibility of inferring causation from the conditioning intervention. While the study did not include a control group for comparison and evaluated relatively short-term outcomes, these design elements eliminated between-groups differences and reduced maturation bias. ${ }^{42}$

The four-month follow-up was chosen to assess the dancers' performance at the farthest period from the intervention, prior to going on a month-long holiday layoff. The authors did not want the results to be skewed due to variance in training with regards to how the dancers chose to use their vacation time. Further follow-up at the end of the season was unattainable secondary to the company touring internationally. Further follow-up beyond that time was impossible due to turnover of company dancers between seasons. The benefit of a short-term follow-up is that it reduces bias due to other training effects and can show if any short-term effects directly following the training program were no longer sustained at a relatively short-term followup, thus suggesting the possible need for continued performance of the conditioning program to maintain training effects. A longer follow-up period would be desirable to better determine sustainability of training effects from the program over a longer period of time. Such a follow-up would be easier attained in a larger company. For small companies such as the one studied, it is unfeasible.

Additionally, the dancers self-selected whether or not to participate, potentially causing selection bias. ${ }^{42}$ However, this type of selection is typical when studying such a specific population as a professional ballet company. Also, because the small sample size was possibly underpowered, ${ }^{42}$ the Wilcoxon signed-rank tests may not have yielded effect sizes as great as the true magnitude of change resulting from the program. Nevertheless, this limitation may not have drastically affected the results as numerous positive changes in physical performance and function following the conditioning class were demonstrated with very conservative testing. 


\section{SUGGESTIONS FOR FUTURE RESEARCH}

Evaluating how a conditioning series may influence dancers' short-term physical function is only the first step in determining the effectiveness of a conditioning class for reducing injury. Future research should focus on evaluating the long-term stability of balance, stability and functional improvements with and without continued conditioning, if the conditioning program physical improvements directly influence injury risk, and if the physical performance changes reported in this study may serve as mediators to injury incidence. Randomized controlled trials with larger sample sizes and reflective of a larger geographical population of dancers may improve validity and generalizability of the results, respectively.

More detailed injury tracking using injury definitions more sensitive than "time-loss"11 or "modified activity"34 may capture additional physical impairments for better testing the effects of conditioning on injury. While these are standard definitions across the current dance medicine literature, the "dancer's mentality,"11,41,43 and the lack of a consensus definition for dance injury 1,34 are well-known challenges for appropriately studying injuries in this population. Future research should focus on streamlining, validating, and possibly standardizing neuromuscular conditioning programs, with a goal of maximizing physical performance benefits and reducing injury risk in the shortest time, with the least financial resources and equipment.

\section{CONCLUSION}

Improvement in multiple PPTs and dance function were noted following the implementation of a neuromuscular conditioning program, but many of the physical gains no longer remained at a four-month follow-up. The loss in improvement at follow-up advocates the potential need for continued conditioning for maintenance of optimal physical performance. The results suggest that conditioning classes may improve professional dancers' physical performance in areas that are related to injury risk. Subsequently, utilizing such programs may serve to decrease injury risk, but more controlled research with larger sample sizes is needed to determine if a cause-effect relationship of neuromuscular conditioning on dance function and injury exists. The results here support the previous recommendation 19 that dance performance may be improved, and injury risk decreased, by applying principles of sports science to professional dancers' training regimens.

\section{CONFLICT OF INTEREST}

The authors report no conflicts of interest.

Submitted: November 10, 2019 CDT, Accepted: October 10, 2020 CDT 


\section{REFERENCES}

1. Smith PJ, Gerrie BJ, Varner KE, et al. Incidence and prevalence of musculoskeletal injury in ballet. Orthop J Sports Med. 2015;3:1-9.

2. Bronner S, Brownstein B. Profile of dance injuries in a Broadway show: a discussion of issues in dance medicine epidemiology. J Orthop Sports Phys Ther. 1997;26:87-94

3. Campoy FA, Coelho LR, Bastos FN, et al. Investigation of risk factors and characteristics of dance injuries. Clin J Sport Med. 2011;21:493-498.

4. Garrick JG, Requa RK. Ballet injuries. An analysis of epidemiology and financial outcome. Am J Sports Med. 1993;21:586-590.

5. Liederbach M, Dilgen FE, Rose DJ. Incidence of anterior cruciate ligament injuries among elite ballet and modern dancers: a 5-year prospective study. Am J Sports Med. 2008;36(9):1779-1788. doi:10.1177/03635 $\underline{46508323644}$

6. Nilsson C, Leanderson J, Wykman A, Strender LE. The injury panorama in a Swedish professional ballet company. Knee Surg Sports Traumatol Arthrosc. 2001;9:242-246.

7. Drezewska M, Sliwinski Z. Lumbosacral pain in ballet school students. Pilot study. J Orthop Trauma Rehabilitation. 2013;15:149-158.

8. Winslow J, Yoder E. Patellofemoral pain in female ballet dancers: correlation with iliotibial band tightness and tibial external rotation. J Orthop Sports Phys Ther. 1995;22:18-21.

9. Winston P, Awan R, Cassidy JD, Bleakney RK. Clinical examination and ultrasound of self-reported snapping hip syndrome in elite ballet dancers. Am J Sports Med. 2007;35(1):118-126. doi:10.1177/0363546 $\underline{506293703}$

10. Smith TO, Davies L, Medici AD, et al. Prevalence and profile of musculoskeletal injuries in ballet dancers: A systematic review and meta-analysis. Phys Ther Sport. 2016;19:50-56.

11. Russell J. Preventing dance injuries: Current perspectives. Open Access J Sports Med.

2013;4:199-210.

12. Roussel NA, Vissers D, Kuppens K, et al. Effect of a physical conditioning versus health promotion intervention in dancers: A randomized controlled trial. Man Ther. 2014;19(6):562-568.
13. Mistiaen W, Roussel NA, Vissers D, et al. Effects of aerobic endurance, muscle strength, and motor control exercise on physical fitness and musculoskeletal injury rate in preprofessional dancers: An uncontrolled trial. J Manipulative Physiol Ther. 2012;35:381-389.

14. Koutedakis Y, Jamurtas A. The dancer as a performing athlete: Physiological considerations. Sports Med. 2004;34(10):651-661. doi:10.2165/000072 56-200434100-00003

15. Angioi M, Metsios GS, Koutedakis Y, et al. Fitness in contemporary dance: A systematic review. Int J Sports Med. 2009;30:475-484.

16. Toledo SD, Akuthota V, Drake DF, et al. Sports and performing arts medicine. 6. Issues relating to dancers. Arch Phys Med Rehabil. 2004;85(1):75-78.

17. Chimera NJ, Warren M. Use of clinical movement screening tests to predict injury in sport. World J Orthop. 2016;7(4):202.

18. Michaelidis M, Koumantakis GA. Effects of knee injury primary prevention programs on anterior cruciate ligament injury rates in female athletes in different sports: A systematic review. Phys Ther Sport. 2014;15:200-210.

19. Twitchett EA, Koutedakis Y, Wyon MA. Physiological fitness and professional classical ballet performance: A brief review. J Strength Cond Res. 2009;23:718-728.

20. Fuhrmann TL, Brayer A, Andrus N, McIntosh S. Injury prevention for modern Dancers: A Pilot Study of an Educational Intervention. J Community Health. 2010;35(5):527-533. doi:10.1007/s10900-010-9223-z

21. Bowling A. Injuries to dancers: Prevalence, treatment, and perceptions of causes. BMJ. 1989;298(6675):731-734. doi:10.1136/bmj.298.6675.7 $\underline{31}$

22. Koutedakis Y, Hukam H, Metsios G, et al. The effects of three months of aerobic and strength training on selected performance- and fitness-related parameters in modern dance students. J Strength Cond Res. 2007;21(3):808-812.

23. Roussel NA, Njis J, Mottram S, et al. Altered lumbopelvic movement control but not generalized joint hypermobility is associated with increased injury in dancers. A prospective study. Man Ther. 2009;14:630-635 
24. Bronner S, Ojofeitimi S, Rose D. Injuries in a modern dance company. Am J Sports Med. 2003;31(3):365-373. doi:10.1177/03635465030310030 701

25. Bronner S, Chodock E, Urbano IER, et al. Psychometric properties of the Dance Functional Outcome Survey (DFOS): Reliability, validity and responsiveness. J Orthop Sports Phys Ther. 2019;49(2):64-79.

26. Hegedus EJ, McDonough SM, Bleakley C, et al. Clinician-friendly lower extremity physical performance tests in athletes: A systematic review of measurement properties and correlation with injury. Part 2-the tests for the hip, thigh, foot and ankle including the star excursion balance test. Br J Sports Med. 2015;49:649-656.

27. Kivlan BR, Carcia CR, Clemente FR, et al. Reliability and validity of functional performance tests in dancers with hip dysfunction. Int J Sports Phys Ther. 2013;8:360-369.

28. Goldbeck TG, Davies GJ. Test-retest reliability of the Closed Kinetic Chain Upper Extremity Stability Test: a clinical field test. J Sport Rehabil. 2000;9(1):35-45. doi:10.1123/jsr.9.1.35

29. Noyes FR, Barber-Westin SD. Neuromuscular retraining intervention programs: Do they reduce noncontact anterior cruciate ligament injury rates in adolescent female athletes? Arthroscopy. 2014;30(2):245-255. doi:10.1016/j.arthro.2013.10.009

30. Pollard CD, Sigward SM, Powers CM. ACL injury prevention training results in modification of hip and knee mechanics during a drop-landing task. Orthop J Sports Med. 2017;5(9).

31. Nessler T, Denney L, Sampley J. ACL injury prevention: What does research tell us? Curr Rev Musculoskelet Med. 2017;10(3):281-288.

32. Malkogeogos A, Mavrovouniotis F, Zaggelidis G, et al. Common dance related musculoskeletal injuries. J Phys Educ Sport. 2011;11(3):259-266.

33. Dillman DA. Mail and Internet Surveys: The Tailored Design Method. 2nd ed. New York: John Wiley \& Sons, Inc.; 2000.
34. Allen N, Nevill A, Brooks J, et al. Ballet injuries: Injury incidence and severity over 1 year. J Orthop Sports Phys Ther. 2012;42(9):781-790.

35. Plinsky PJ, Rauh MJ, Kaminski TW, et al. Star excursion balance test as a predictor of lower extremity injury in high school basketball players. $J$ Orthop Sports Phys Ther. 2006;36:911-919.

36. Gamboa JM, Roberts LA, Maring J, Fergus A. Injury patterns in elite preprofessional ballet dancers and the utility of screening programs to identify risk characteristics. J Orthop Sports Phys Ther. 2008;38(3):126-136.

37. Okada T, Huxel KC, Nesser TW. Relationship between core stability, functional movement, and performance. J Strength Cond Res. 2011;25(1):252-261.

38. Mills JD, Tauton J, Mills W. The Effects of a 10-week training regimen on lumbo-pelvic stability and athletic performance in female athletes: A randomized controlled trial. Phys Ther Sport. $2005 ;(6): 60-66$.

39. Garrick JG, Requa RK. Ballet injuries: An analysis of epidemiology and financial outcome. Am J Sports Med. 1993;21(4):586-590. doi:10.1177/036354659302 $\underline{100417}$

40. Lee L, Reid D, Cadwell J, et al. Injury incidence, dance exposure and the use of the movement competency screen (MCS) to identify variables associated with injury in full-time pre-professional dancers. Int J Sports Phys Ther. 2017;12(3):352-370.

41. Wainwright SP, Williams C, Turner BS. Fractured identities: Injury and the balletic body. Health. 2005;9(1):49-66. doi:10.1177/1363459305048097

42. Jewell D. Guide to Evidence-Based Physical Therapy Practice. 2nd ed. Sundbury, MA: Jones \& Bartlett Learning; 2011.

43. Shah S. Caring for the dancer: Special considerations for the performer or troupe. Curr Sports Med Rep. 2008;7(3):128-132. doi:10.1097/01.cs mr.0000319716.56169.29 


\section{SUPPLEMENTARY MATERIALS}

\section{Appendix 1}

Download: https://ijspt.scholasticahq.com/article/21150-the-impact-of-dance-specific-neuromuscular-conditioningand-injury-prevention-training-on-motor-control-stability-balance-function-and-injury-in-pr/attachment/53517.pdf 